\title{
Using Crowdsourcing to Expand the Resource Base of Business
}

\author{
Elena Gafforova ${ }^{1}$, Natalia Merkushova ${ }^{1}$, Vladimir Smirnov ${ }^{1}$, Valentina Batalova ${ }^{1} \&$ Yulia Merkushova $^{2}$ \\ ${ }^{1}$ Far Eastern Federal University, Vladivostok, Russian Federation \\ ${ }^{2}$ Saint-Petersburg State University of Economics, Russian Federation \\ Correspondence: Vladimir Smirnov, Far Eastern Federal University, st. Sukhanov, 8, Vladivostok, 690091, \\ Russian Federation. E-mail: vla102@yandex.ru
}

\author{
Received: October 25, 2014 Accepted: December 13, 2014 Online Published: March 16, 2015 \\ doi:10.5539/ass.v11n7p91 URL: http://dx.doi.org/10.5539/ass.v11n7p91
}

\begin{abstract}
The article shows the essence of crowdsourcing as a modern management technology, as the basis for innovative business models and as a way of expanding the resource base of business. It figures out the structural elements of crowdsourcing, the advantages and disadvantages of crowdsourcing and problems associated with the use of crowdsourcing technology.
\end{abstract}

Keywords: crowdsourcing, resources, entrepreneurship, management technology, business model, motivation

\section{Introduction}

The transition from the competition of products and services to compete at the level of business models is a distinctive feature of the modern economy (Ivanova \& Leydesdorff, 2013). The basis of this transition are innovative technologies and management techniques. Benchmarking, outsourcing, crowdsourcing and their varieties are of such technologies.

Benchmarking and outsourcing have a lot in common. They are united firstly in certain actions performed by the organization, and secondly, the predictability of results. Crowdsourcing differs from benchmarking and outsourcing by uncertain actions and results.

By the definition of J. Hove crowdsourcing is the transfer of certain production functions to the public on the basis of a public offer without a contract. Crowdsourcing is the use of collective intelligence and synergy interaction of a large number of people (Howe, 2012).

J. Shuroveski in his book "Wisdom of Crowds" shows that searching a solution to a problem relying on the combined knowledge of many people, when conditions are prescribed properly, may be more effective method than the use of experts. The crowd can be smart if it is diverse, decentralized and has the opportunity to express their opinion as a consensus (Shuroveski, 2007).

Experts note the different characteristics and forms of crowdsourcing. They are:

- $\quad$ Technology to identify and use knowledge of citizens (Howe, 2009; Lathrop \& Ruma, 2010);

- Business model for citizens in conditions of growing variety of government initiatives (Linders, 2011);

- $\quad$ Competence crowdsourcing system (Kazman \& Chen, 2009);

- Digital ecosystem for e-participation of citizens in public life (Saad-Sulonen, 2010);

- Community of people and computers as a single ecological system that allocates different types of crowdsourcing, uses game theory and where participants can chose different strategies of behavior (Das \& Vukovic, 2011);

- Basic concepts of crowdsourcing and examples of crowdsourcing projects based on platforms Maps Google, Wiki, Amazon's Mechanical Turk, Ushahidi (Greengard, 2011);

- Changing of citizens' behavior, users' active participation in the development of any system, not only in its use (Dick et al., 2011);

- The basics of environmental design of complicity, the organization of citizen participation in the development of a document or repository of knowledge (Hagen \& Robertson, 2010);

- $\quad$ Direction to solution of semistructured social problems (Brown et al., 2010; Fitzpatrick, 2003);

- Technologies and techniques that solve complex social problems through public consultations, joint networking activities aimed at the creation and improvement of (Conklin, 2006; Munneke et al., 2007; Weber \& Khademian, 2008). 


\section{Methods}

Crowdsourcing is a complex variety of actions to attract the efforts of society for the challenges. Search among consumers suggestions that can improve the quality of products, called "crowdstorming" (an example is the project "Dell Ideastorm"). Actions aimed at finding people and organizations able to meet the challenges facing the various departments of large corporations, are "crowdcasting" (an example is the project "Innocentive"). Activities that are carried only by the efforts of open network community can be defined as "crowdmanufacturing" ("Wikipedia", "Linux")

There are two types of crowdsourcing. Crowdsourcing based on competition (tournament-based) and crowdsourcing based on cooperation (collaboration-based). There are three areas of crowdsourcing. These are crowdcreation, crowdwoting and crowdfounding (Leimeister, 2010). Crowdcreation aims to provide ideas, solutions, concepts, design projects. Crowdwoting is more to do with political control - a poll vote, assessment bills. Crowdfounding (Mollick, 2014) is the way of collective financing activities and projects through the Internet.

Consequently, crowdsourcing is a general term for a group of various control technologies. These management techniques have common features. They all use the potential of the crowd. Growth of scientific knowledge in this field of research can be achieved through the application of a systematic approach, and the use of methods of analysis, synthesis, grouping and classification.

\section{Results}

The successful development and expansion of the scope of crowdsourcing based on a better understanding of it's nature. And it is associated with the current practice of scientific generalization of its use.

Widespread crowdsourcing is usually explained the development of Internet and mobile communications. According to the authors, the development of the Internet and mobile communications is the only prerequisite for the spread of crowdsourcing. Condition of its development is the change in the level and nature of consumption. In recent decades, for a large part of the population in developed countries, problems of survival overshadowed. To the fore the need of creativity and self-realization, participation in management, peer recognition, leadership. The main factor in the development of crowdsourcing is a risky business as innovative activities to create a new fund for business income. "The essence of business is to create a new fund in order to obtain business income" (Smirnov, 2014). Entrepreneurs in the process of crowdsourcing productively use the resources of society, creating new social capital.

Crowdsourcing should be considered, firstly, as a component of business model innovation, aimed at solving particular problems of business and management, and secondly, as a basis for a business model, and thirdly, as a way to expand the resource base of the enterprise organization.

\subsection{Crowdsourcing as a Component of Business Model Innovation}

Crowdsourcing for innovative business models are widely used as a method of management, aimed at solving particular problems of business and management.

1) A small part of the routine tasks of identifying, sorting, and the implementation of other private action under the global projects of collective science.

"People's Map" of "Yandex" is the most famous Russian project in this direction. Everyone is welcome to add to the map, made on the basis of satellite images of the professionals, the new object or comment on the organizations located in a particular building. New information appears on the official map "Yandex" after verification.

2) Development of innovation in various industries. According to the theory of "closed innovation", all laboratory development were to be kept secret from competitors, and any external sources of new ideas is usually perceived as questionable or even dangerous. But today, the potential of scientists working within the company, is not sufficient for the formation of new markets and the victory over the competition. It requires innovation in the way of creating innovation. An open innovation for the first time said $\mathrm{H}$. Chesbrough (Chesbrough, 2003).

An example of the transition to the concept of open innovation on the basis of crowdsourcing is the activity of Lego (Antorini et al., 2012).

3) Collection and analysis of proposals to improve the product, service or process. Microsoft proposed to discuss the Internet program Windows7, is under development. Its tested by millions of people around the world, including in Russia, and expressed their wishes. Automotive company Fiat Group in 2009 launched the online 
platform FiatMio. A year later, at the auto show in Brazil appeared Fiat Mio FCC III. He was the result of more than 9000 members, which together suggested 6,800 different ideas.

4) Perform one of the general or specific management functions of the company. Mexican mining corporation Goldcorp posted maps of their fields and 3D-models of mine on the Internet, allowing geologists to look for gold on its territory (function - production planning). Thousands experts analyzed the information, the most successful received gratuity, and previously unprofitable company earned through crowdsourcing $\$ 3$ billion.

GetJar company created an online community for testing products that are offered for free download (function control) (Dorohov \& Gubskii, 2013).

Russian media holding "CTC Media" launched a web project, where users could imagine their continuation of the series (function - product design).

One of the large-scale applications of crowdsourcing is to attract funds for various projects (feature - the organization of financing). This approach is used as part of a separate business, and as an independent business model.

\subsection{Crowdsourcing Is the Basis of Business Models}

This occurs when the majority of the functions performed on the basis of crowdsourcing or on the main function is crowdsourcing.

One of the first uses of technology as a crowdsourcing business model occurred when distributing software Lunix. It is not intended commercial purpose, spread the ideology of freedom (Shengelya, 2012). Currently, this business model, commonly known as the concept of open source and it is widely used in many other areas.

Company Treehouse Labs developed and launched a mass production system BiKN. RFID-reader that is compatible with the iPhone, helps to determine presence of things, children, pets, and the phone itself. The platform of this program is built using open industry standards. Treehouse Labs offers to other companies to use it to complement their own sensors and applications (Vensedorina \& Makeev, 2013).

In 2005, R. Nielsen created the project "open beer." This project is being developed due to creative crowdsourcing. Anyone can make a beer for this recipe (Bocharsky, 2012).

An example of a business model based on crowdsourcing is the work of the company Threadless, that produces clothing for the sport. In the Japanese furniture company Muji five thousand participants, registered on the site, offer ideas. Threadless and Muji launches only that deserved recognition of consumers at the stage of concept.

An example of a specific business model based on crowdsourcing is the work site busuu.com. This innovative online community for learning foreign languages according to the scheme $\mathrm{p} 2 \mathrm{p}$ (peer-to-peer). Tens of thousands of people check out other people's exercise in their own language, and instead use the same service from the partners. Total number of users is more than 7 million people. Founders of the resource receive income through advertising and selling additional products.

Opportunities for the application of crowdsourcing as a basis of innovative business models, its prospects and demand in many areas have become the basis for the existence of companies like InnoCentive (research and development), 99designs.com, Redesignme.com (designs), Ideabounty.com, Atizo.com (marketing), CroudSpring.com (problem solving small business), Kickstarter.com (a platform to raise funds for various projects). The main activity of the company - the provision of services on the organization of crowdsourcing projects on request. In Russia, this market niche is interactive creative agency E-Generator, part of the holding "Finns". His clients include Unilever, Yandex, Kaspersky Lab and others.

\subsection{Important Elements of Crowdsourcing}

Important elements of crowdsourcing are members, the organization of the process, the motivation of participants.

\subsubsection{Participants Crowdsourcing}

In the process of crowdsourcing include the interaction of the customer, numerous participants, as well as consumers of the results of ongoing projects. Customers are state and public organizations and private companies. At the state level crowdsourcing is used to analyze and propose solutions to the problems of public administration.

In early 2012, the Government of Finland launched a project called "Civil Initiative" through which registered users can themselves propose a draft law. Elements of crowdsourcing used successfully in Latvia, in the municipality of Munich. Iceland is an example of a country whose Constitution was written using crowdsourcing 
technology. In Russia, the goal of "Big Government" is to foster interaction between the authorities and society through the accumulation of constructive proposals for the adoption of new and modernization of existing laws. Under the project "Russia without fools' users are registered and then leave the description of administrative barriers with the names of the organizations and the names of those responsible. However, not all posts will be published on the portal. In the first place, attention will be paid to the facts that affect the lives of many people.

Other projects are aimed at the discussion, analysis and improvement of the legal field. In the Russian Federation, the web portal "Your laws" is an independent platform for the discussion of bills. Public platform to discuss bills organized online zakon.profsro.ru. Collective creation of hypertext (wiki) and selection of the most promising proposals by a vote (vote) occurs on the platform WikiVote. New technology document collaboration is widely used in the field of e-government and open government. In 2011 - 2012 years on the basis of technology and methodology WikiVote projects were implemented "Public construction of the image of the Russian school graduates in 2020" and "Public consultations on the Education Law in the Russian Federation" (Burov et al., 2012). Crowdsourcing is becoming a hallmark of today's Russian policy that fosters trust between citizens and government.

Crowdsourcing involves a large number of participants. These may be external and internal to an organization. Using crowdsourcing among employees in order to obtain proposals for the improvement of the organization gives positive results in large organizations. Savings Bank of the Russia organized on its website a number of external crowdsourcing projects (no queues, non-credit products for small, medium and large businesses, and others). It also offers its employees to express themselves by participating in the creation of the document "Policy innovation in the bank" (Dolzenko, 2014). Similar programs, allowing to provide the flow of innovative ideas from employees, there are companies Lukoil ("Bank of ideas and innovation," from 2011), TNK-BP ("Bank of Ideas", from 2009), Rosneft ("Bank Innovation "," Bank technology "), Alpha Bank (" Alfa-idea "), and others (Garipov, 2013).

Many universities through their own websites attract staff, students and everyone to the statement of proposals to improve the various aspects of the activities of higher education. The success of the "internal" crowdsourcing is the reason for bringing to market the relevant software. For example, service Tell Your Boss Anything allows any employee to send the head of an anonymous letter with information about the shortcomings of and ideas for improving the activity (Upatov, 2012).

Consumers of crowdsourcing results can be not only its customers, but also the whole society or a part thereof. For example, a project of Greenpeace in Russia, "The Second Life of things - Map points Reception recycled" aims to create an interactive map of available recyclables collection points in the population with the ability to fill the part of the inhabitants of the cities. Work on filling the card, its modeling and development on a voluntary basis. Cards have already taken advantage of more than 500 thousand people. The popularity of the card continues to grow (Crowdsourcing, 2012).

\subsubsection{Organization of the Process of Crowdsourcing}

Specificity of crowdsourcing is to attract a large audience to the tasks. Special requirements apply to its organization to ensure the quality of the final result.

Selection of participants in the project is made to improve the quality of the results of crowdsourcing or dropout enough competent and active participants.

Some of the projects initially focused on a limited audience. For example, a common practice for radio stations is the reference to the category of motorists with a request to report on the situation on the roads.

The authors of the book "Building of business models" by A. Osterwald and I. Pine created an online community for tips, comments, share experiences. This allowed the authors to name co-author of 470 practitioners from 45 countries (Osterwald \& Pine, 2012).

Company InnoCentive, founded by former employees of the pharmaceutical corporation Eli Lilly and Company for money your employer initiated 20 crowdsourcing projects. Each project employed several thousand people, all involved about 100 thousand people who came to the resource received tasks and generate ideas. Screenings of participants was carried out with the help of experts or voting members. Limited group of the most competent and motivated participants further elaborated proposals.

Lego Company created various platforms for crowdsourcing. This allowed to attract innovators with different levels of skills. The company also uses the forums for groups of users, experts and virtual classrooms projects (Antorini et al., 2012). 
Organization of interaction between the participants is made to produce the best solution. Communication between the participants can be effective. In developing the Galaxy Zoo project, based on the communication between members of the study was initiated new to science objects and phenomena. In Russian practice of the Agency for Strategic Initiatives has the same goal.

The wording of the task and the initial restrictive conditions must be correct, unambiguous. Activities of the parties shall be subjected to repeated scrutiny. The project Galaxy Zoo each picture demonstrates several volunteers. Version of the classification adopted by the coincidence in $80 \%$ of cases (Dobrynin, 2012).

The procedure for selecting the best solution is formed by expert methods or by vote. Voting should consider different possibilities.

\subsubsection{Motivation of Participants}

Motivational expectations performers crowdsourcing projects are as follows: payment; altruism; sense of belonging to the most important events and processes; pleasure; reputation; to get a job (Doan et al., 2011).

A significant part of the business models using crowdsourcing does not involve the payment of participants of any monetary compensation. As motivators actively used intangible factors. For example, the Canadian enthusiast B. Hudson, who worked with the project Stardust @ home almost since its inception, allowed to give a name found in 2010 particle. In 2009, in the scientific astronomical publication "Monthly notes of the Royal Astronomical Society" published an article describing a new kind of galaxies, open forum with the participation of users Galaxy Zoo, which were included in the list of sponsors. Russian Journal "The secret of the company" in the pages of his publication offers everyone to take part in solving business problems in the areas of strategic development. Later in the magazine analyzes the proposals made, the authors point out the best solutions, but is also determined by the worst solution (without author). The agency's strategic initiatives to reward active members of organized free access to leading industry forums, meetings with representatives of government, public and commercial organizations, awarding special prizes from Witology.

Cash payments are in serious projects that require special knowledge and a lot of time to get the result. The amount of remuneration for the American company InnoCentive depends on the skill level of participants, ranging from $\$ 10,000$ to $\$ 100,000$ for the project. In addition, customers pay for InnoCentive the possibility of appeal to the famous experts. Author innovation that the company Lego ends successful project and exit model on the market gets $1 \%$ of the net profit generated by the product. The site Quirky.com can invent your own household items and gadgets.

Goodwill motivation of participants necessarily stored in the case of payment of compensation. Thus, the main prize for the winner in the field of design t-shirts manufactured by Threadless, is the author's name on the label of each product.

The main task of motivating the participants is to build the original system of rewards, including promotion, virtual medals, ratings, ownership of virtual currency (for example, "Vito" on the platform witology).

\section{Discussion}

Crowdsourcing has a wide field for use as a basis element and innovative business models, effective way to expand the resource base of an entrepreneurial organization. However, it has not only advantages but also disadvantages.

The advantages of crowdsourcing are:

- Minimizing labor and research costs for dealing with emerging problems;

- $\quad$ Receiving innovative ideas;

- Identifying problem areas;

- Increasing customer loyalty, the company's value, brand;

- The ability to attract a permanent job the most promising project participants;

- The ability to find a specialist with a narrow specialization;

- Demonstration of business transparency and cooperation;

- Reduction of risks associated with the uncertainty of demand in the market.

- The disadvantages of crowdsourcing are:

- The inability to fully monitor the progress and plan the result;

- Poor quality of issued decisions, redundancy and duplication of information from participants, which require time and resources for processing, additional checks;

- High demands on the organization of the systems of interaction and feedback; 
- The need for a high level of motivation of the participants.

Widespread business models based on crowdsourcing in all fields requires solving a number of problems.

The problem is to construct a system of evaluation decisions. Using the method often involves users vote for their favorite product idea. However, by Theorem Gibbard-Satterthwaite any decision-making process, where the vote submitted three variants may be associated with the manipulation (Karabekyan, 2012).

Problem is the improvement of the evaluation of the effectiveness of crowdsourcing. Currently used to assess the quantity and quality of ideas, savings, increase the value of a brand or company, the amount of borrowed resources. Economic performance is evaluated from the perspective of the organizers of crowdsourcing. Social effectiveness in crowdsourcing projects have a high value, but cannot always be determined.

The problem is also to improve the software. Software is a key resource in business models with the use of crowdsourcing. The software is used in the organization of projects related to the ballot for the development of a law at the national level, to ensure the identification of the citizen, the keeping of their personal data, the reliability of an electronic signature, in other cases.

Rather complex problem is to find original and effective solutions in the area of support the continued interest of the participants. Motivation decreases with time. The main directions of the motivation of participants crowdsourcing business models according to their degree of influence of the following: self-realization and improvement of the social role, including in the game, getting material goods or services. Their implementation in specific projects will largely provide the necessary level of motivation of participants and, consequently, the success of the business model.

\section{Conclusions}

The emergence and development of crowdsourcing introduces significant changes in the management of the business organization. On the basis of crowdsourcing is expanding the resource base of business structures. Entrepreneurs in the process of crowdsourcing productively use the resources of society, creating new social capital. Progress in the field of communications, changing consumption patterns of the population, ensure the development of entrepreneurial behavior crowdsourcing. Business model based on crowdsourcing can effectively address a wide range of problems of varying complexity in resource-limited settings.

Development of crowdsourcing needs to neutralize its negative manifestations and solve the problems of building a system of assessment decisions, developing performance evaluation system of crowdsourcing, improve the software you use, support the continued interest of the participants.

\section{References}

Antorini, M., Muniz, A. Jr., \& Askildsen, T. (2012). Community collaboration consumers: Lessons from the Lego Group. My business, 6, 82-89.

Bocharsky, K. (2012). Markets and niches. The secret of the firm, 12, 72-75.

Brown, V. A., Harris, J. A., \& Russell, J.Y. (2010). Tackling wicked problems through the transdisciplinary imagination. Earthscan.

Burov, V. V., Yokes, B. B., \& Patarakin, E. D. (2012). Promotion of social innovation through public construction documents. Educational Technology \& Society, 15(2), 517-528.

Chesbrough, H. W. (2003). The Era of Open Innovation. Sloan Management Review, 44(3), 35-41.

Conklin, E. J. (2006). Dialogue mapping: building shared understanding of wicked problems. Wiley.

Crowdsourcing the guardian of nature. (2012).

Das, R., \& Vukovic, M. (2011). Emerging theories and models of human computation systems: a brief survey. Proceedings of the 2nd international workshop on Ubiquitous crowdsouring (pp. 1-4). New York: ACM.

Dick, H., Eden, H., \& Fischer, G. (2011). From consumers to owners: Using meta-design environments to motivate changes in energy consumption. Proceedings of the Third international conference on End-user development (pp. 319-324). Berlin: Heidelberg. Springer-Verlag.

Doan, A., Ramakrishnan, R., \& Halevy, A. Y. (2011). Crowdsourcing Systems on the World-Wide Web. Communications of the ACM, 54, 486-496.

Dobrynin, S. (2012). Laptops to the Galaxy. Around the World, 7, 116-121.

Dolzenko, R. A. (2014). The possibility of organizing and using crowdsourcing projects in the commercial bank. 
Bulletin of Tomsk State University, 379, 154-159.

Dorohov, R., \& Gubskii, A. (2013). "I was a kid, bathed in the cache" - Ilya Laursen, founder of GetJar. Vedomosti, 115, 3377.

Fitzpatrick, G. (2003). Locales Framework: Understanding and Designing for Wicked Problems. Norwell.

Garipov, A. (2013, July 29). Innovative crowdsourcing in Russia. Oil newspaper.

Greengard, S. (2011). Following the crowd. Commun. ACM, 54(2), 20-22.

Hagen, P., \& Robertson, T. (2010). Social technologies: challenges and opportunities for participation. Proceedings of the 11th Biennial Participatory Design Conference (pp. 31-40). New York: ACM.

Howe, J. (2009). Crowdsourcing: Why the power of the crowd is driving the future of business.

Howe, J. (2012). Crowdsourcing. Collective intelligence as a tool for business development. Alpina Publisher.

Ivanova, I. A., \& Leydesdorff, L. (2013). Rotational Symmetry and the Transformation of Innovation Systems in a Triple Helix of University-Industry-Government Relations. Technological Forecasting and Social Change. http://dx.doi.org/10.1016/j.techfore.2013.08.022

Karabekyan, D. (2012). For Fair Elections. Around the World, 8, 20-22.

Kazman, R., \& Chen, H.-M. (2009). The metropolis model a new logic for development of crowdsourced systems. Commun, ACM, 52(7), 76-84.

Lathrop, D., \& Ruma, L. (2010). Open Government: Collaboration, Transparency, and Participation in Practice (1st ed.). O’Reilly Media.

Leimeister, J. M. (2010). Crowdsourcing. Crowdfunding, Crowdvoting, Crowdcreation. Robert Risse. Steuercontrolling und reporting. Konzernsteuerquote und deren Bedeutung fuer das Steuermanage-ment (pp. 388-392). Deutschland: Springer Gabler.

Linders, D. (2011). We-Government: an anatomy of citizen coproduction in the information age. Proceedings of the 12th Annual International Digital Government Research Conference, Digital Government Innovation in Challenging Times (pp. 167-176). New York: ACM.

Linders, D., \& Wilson, S. C. (2011). What is open government?: One year after the directive. Proceedings of the 12th Annual International Digital Government Research Conference, Digital Government Innovation in Challenging Times (pp. 262-271). New York: ACM.

Mollick, E. (2014). The dynamics of crowdfunding: An explorary study. J. of Business Venturing, 29(1), 1-16.

Munneke, L. (2007). Supporting interactive argumentation: Influence of representational tools on discussing a wicked problem. Comput. Hum. Behav., 23(3), 1072-1088.

Osterwald, A., \& Pine, I. (2012). Building of business models. Alpina Publisher.

Saad-Sulonen, J. (2010). E-Participation as an information ecology: a micro-scale examination of two cases in Helsinki. Proceedings of the 22nd Conference of the Computer-Human Interaction Special Interest Group of Australia on Computer-Human Interaction (pp. 384-387). New York: USA, ACM.

Shengelya, Q. (2012). I got angry and decided to build a world of freedom. Around the World, 4, 119-122.

Shuroveski, J. (2007). Wisdom of Crowds. Why we are smarter together than alone, and as a collective mind forms of business, economy, society and the state. Moscow: OOO "ID Williams".

Smirnov, V. P. (2014). Using scientific reflection in the study of entrepreneurship. Life Sci. J., 11(9s), 303-306.

Upatov, A. (2012). Service Tell Your Boss Anything (IT for the entrepreneur). My business, 12(64).

Vensedorina, O., \& Makeev, S. (2013). Lost and Found. My business, 1(11).

Weber, E. P., \& Khademian, A. M. (2008). Wicked Problems, Knowledge Challenges, and Collaborative Capacity Builders in Network Settings. Public Administration Review, 68(2), 334-349.

\section{Copyrights}

Copyright for this article is retained by the author(s), with first publication rights granted to the journal.

This is an open-access article distributed under the terms and conditions of the Creative Commons Attribution license (http://creativecommons.org/licenses/by/3.0/) 